Body temperature changes during inflammation: their mediation and nutritional significance

By Matthew J. Kluger, Department of Physiology, University of Michigan Medical School, Ann Arbor, Michigan 48109, USA

\title{
Fever defined
}

Although fever has often been defined as any elevation in body temperature, this definition would result in considerable confusion between true fever and hyperthermia. In fever, as a result of the elevated thermoregulatory 'set-point', a person's heat production increases, while at the same time heat loss decreases. Snell \& Atkins (1968) defined four categories of body temperature based on the set-point theory of temperature regulation:

(a) Normothermia, where set-point and actual body temperature coincide. This condition occurs during most of the time.

(b) Hypothermia, where set-point may or may not be normal, but actual body temperature is below this set-point. Hypothermia can occur as a response to a drug, disease or exposure to the cold.

(c) Hyperthermia, where set-point may or may not be normal, but actual body temperature is higher than this set-point. Hyperthermia can occur as a response to a drug, disease or exposure to a warm environment.

(d) Fever, where set-point is raised and deep body temperature may or may not be raised to the same level.

Studies with human subjects (e.g. Cooper et al. 1964; Cabanac \& Massonnet, 1974) and with experimental animals (e.g. Cabanac et al. 1970; Sharp \& Hammel, 1972; Vaughn et al. 1974; Satinoff et al. 1976) have shown that the thermoregulatory set-point is indeed raised during fever.

\section{What causes fever?}

For many years, fever in response to endotoxin or purified lipopolysaccharide (LPS) or other 'exogenous pyrogen', was assumed to be caused by the release into the blood of a small protein known as 'endogenous pyrogen' (EP) from activated macrophages. The basis for this elegant hypothesis has been summarized often (e.g. Atkins \& Bodel, 1974; Kluger, 1979; Atkins, 1982). Briefly, Billroth (1864-5) and Weber (1864) showed that pus from wounds contained fever-inducing factors. The term 'pyrogen' was coined by Burdon-Sanderson (1876) for a fever-inducing substance that was extracted from putrid meat. This factor, presumably endotoxin, was considered to be an 'exogenous' pyrogen. Menkin (1944) was able to isolate what he thought to be a peptide from inflammatory exudates; this material was called 'pyrexin'. Beeson (1948) showed that injection of a pyrogen-free salt solution into the peritoneal cavity of rabbits resulted in the liberation of a pyrogen from the leucocytes that migrated into this area. These 'endogenous' pyrogens were assumed to be coming from polymorphonuclear granulocytes. It is now thought that most of this EP was coming from mononuclear cells.

A variety of studies also led to the conclusion that circulating EP produced fever by acting on the central nervous system. For example, King \& Wood (1958), found that an injection of EP into the carotid arteries of rabbits resulted in fevers of shorter latencies 
and greater magnitude than those resulting from injections into veins. Cooper et al. (1967), Jackson (1967), and others showed that injection of minute quantities of EP into the anterior hypothalamus produced fever. However, these earlier experiments taken together only demonstrated that endogenous pyrogen was capable of producing fever (at the level of the anterior hypothalamus). The key question that was never addressed was: is fever in response to injection of an exogenous pyrogen quantitatively accounted for by an increase in the circulating concentration of EP (and the subsequent elevation of EP in the anterior hypothalamus)?

Subsequently, scientists working in the area of fever research came to the conclusion that interleukin-1 (IL-1 $\alpha$ and $\beta$ ) is equivalent to EP (e.g. Dinarello, 1984; Oppenheim, $1986)$. IL-1 $\alpha$ and IL-1 $\beta$ are peptides produced by a variety of phagocytic cells that are thought to influence virtually every aspect of the stereotyped 'acute-phase response' to infection and inflammation (Dinarello, 1984; Kluger et al. 1985; Oppenheim, 1986). These cytokines are thought to be responsible for stimulating T-cells, for lowering the plasma concentrations of iron and zinc and raising that of copper, increasing slow-wave sleep, causing many of the aches and pains associated with infection, suppressing food appetite, stimulating the production of many acute-phase proteins, and others (see Table 1). It is, however, now apparent that other cytokines such as tumour necrosis factor (TNF) (Dinarello et al. 1986; Kettelhut \& Goldberg, 1988), interferon- $\alpha$ (Dinarello et al. 1984; Feldberg \& Scott, 1984), interferon- $\gamma$ (Morimoto et al. 1987), and interferon- $\beta_{2}$

Table 1. Reported actions of interleukin-1 (IL-1) and tumour necrosis factor (TNF) (based largely on Nathan (1987) as modified by Kluger \& Liu (1989))

$\begin{array}{ll}\text { Target } & \text { Action } \\ \text { T-lymphocytes } & \text { Co-mitogenesis } \\ \text { Chemotaxis } & \text { Co-mitogenesis } \\ \text { B-lymphocytes } & \text { Ia antigen expression } \\ & \text { Chemotaxis } \\ \text { Increased cytotoxicity } \\ \text { Natural killer-cells } & \text { Interleukin-2 receptors } \\ \text { Mononuclear phagocytes } & \text { Differentiation of precursors } \\ & \text { Induction of cytotoxic, antimicrobial and reactive } \\ \text { oxygen intermediates secretory capacity } & \text { Secretion of IL-1 and TNF } \\ & \text { Thromboxane } \\ & \text { Chemotaxis } \\ & \text { Inhibition of precursors } \\ \text { Degranulation, lysosomal enzyme release } \\ \text { Secretion of reactive oxygen intermediates } \\ \text { Thromboxane } \\ \text { Enhancement of phagocytosis, ADCC } \\ \text { Adhesion to endothelium } \\ \text { Surface display of C3bi receptors } \\ \text { Chemotaxis } \\ \text { Toxicity to schistosomes } \\ \text { Adhesion to endothelium }\end{array}$


(Table I continued)

Target

Endothelium

Fibroblasts

Synoviocytes

Chondrocytes

Osteoclasts

Osteoblasts

Adipocytes

Hepatocytes

Astroglia

Mesangial cells

Pancreatic islets

Tumour cells

In vivo, loci of action not certain
Action

Enhanced proliferation

Induction of procoagulant activity

Decreased synthesis of plasminogen activator, decreased activation of protein C, increased synthesis of plasminogen activator inhibitor

Platelet-activating factor, $\mathrm{PGE}_{2}$, prostacyclin, Von Willebrand factor

IL-1

G/M-CSF, G-CSF, M-CSF, multilineage-CSF

Induction of HLA-A, B antigens, p100.120 antigen

Induction of ELAM-1, ICAM-1

Adhesion of neutrophils, monocytes, lymphocytes, natural killer-cells

Platelet-derived growth factor

Increased proliferation

Synthesis of $\mathrm{PGE}_{2}$, collagenase

Interferons including interferon $\beta-1$ or $\beta-2$, or both

Protease inhibitor

Hyaluronidase (EC 4.2.2.1)

GM-CSF

IL-1

Expression of HIA-A, B antigens

Antiviral activity

Decreased synthesis of proteoglycans

Increased proteoglycanase, collagenase

PGE $_{2}$

Increased proliferation and bone resorption

Decreased bone synthesis

Decreased synthesis of lipoprotein lipase (EC 3.1.1.34)

Induction of serum amyloid $A$ and $P$ complement factor $B$ haptoglobin $\alpha$-2-macroglobin

Inhibition of albumin synthesis

Increased proliferation

Increased proliferation

Neutral protease secretion

Cytotoxicity

Cytotoxicity

Antiviral activity

Haemorrhagic necrosis of some tumours

Increased plasma ACTH, corticosteroids

Increased turnover of plasma amino acids

Decreased plasma iron, zinc

Decreased plasma glucose

Accumulation of neutrophils

Epidermal hyperplasia, fibrosis

Decreased lethality from radiation

Decreased food intake

Fever

Increased slow-wave sleep

$A D C C$, antibody-dependent cell-mediated cytotoxicity; C3bi, number of type of receptor; $P G E_{2}$, prostaglandin $E_{2} ; C S F$, colony stimulation factor; $G$, granulocyte; $M$, macrophage; HLA-A, histocompatibility complex loci-A; ELAM-1, endothelial leukocyte adhesion molecule-1; ICAM-1, intracellular adhesion molecule-1; ACTH, adrenocorticotrophic hormone. 
(now known as interleukin-6 or IL-6; Nijsten et al. 1987), are also capable of producing many of these acute-phase responses, including fever, when injected into experimental animals. Based on the historical development of our understanding of the pathogenesis of fever, the assumption has generally been made that intravenous or intraperitoneal (i.p.) injection of LPS results in an elevation in the circulating concentration of IL-1 (or these other mediators). It is further assumed that IL-1 then crosses areas in the blood-brain barrier that are leaky and, in or near the anterior hypothalamus, causes an elevation in the thermoregulatory 'set-point', resulting in both physiological and behavioural responses that cause body temperature to rise.

The fever that occurs following injection of these cytokines is thought to be mediated primarily by the release of prostaglandins in or near the region of the hypothalamus (Bernheim, 1986; Stitt, 1986). Antipyretic drugs, such as aspirin, are thought to exert their temperature-lowering action by blocking the synthesis of prostaglandins, and thus returning the thermoregulatory set-point to its afebrile level.

There is, however, no direct quantitative evidence that IL-1, TNF, or any other mediator currently assumed to be a circulating EP actually accounts for the fevers (or other acute-phase responses) induced by injection of LPS or other exogenous pyrogen. Evidence purporting to show this relationship suffers from the same serious problem as the earlier work with EP; that is, in virtually all the studies used to determine the effects of a mediator, it is not known whether the concentrations of the mediator used in the experiments achieve plasma concentrations similar to those that occur in vivo. For example, Tocco-Bradley et al. (1986) have shown that in order to induce a fever in the laboratory rat they had to infuse intravenously 7500 units recombinant murine $1 \mathrm{~L}-1 / \mathrm{h}$. We have estimated that, even if this IL-1 were being cleared with a half-life of $2 \mathrm{~min}$, as suggested by Kampschmidt \& Jones (1985), the plasma concentration of IL-1 would be considerably greater than 10 units IL-1/ml, a concentration much higher than that measured by anyone to date. In Kettelhut \& Goldberg's (1988) study they injected rats i.p. with $10^{5}$ units/g TNF (approximately $10^{7}$ units TNF) to produce large fevers that lasted about $7 \mathrm{~h}$. In ongoing studies conducted in our laboratory, we have found that injecting rats with a dose of LPS that produced a fever similar to that reported by Kettelhut \& Goldberg (1988) resulted in variable increases in the plasma concentration of TNF from approximately $10 \mathrm{units} / \mathrm{ml}$ to about $600 \mathrm{units} / \mathrm{ml}$, probably far less than would be found following injection of $10^{7}$ units TNF.

Another putative EP is IL-6. At the International Workshop on Monokines and Other Nonlymphocytic Cytokines, Billiau \& van Damme (1987) have shown that IL-1, TNF, and other mediators stimulate the production and release of IL-6. Nijsten et al. (1987) have shown that the body temperature of patients with severe burns correlates with plasma concentration of IL-6, and they concluded that 'IL-6 plays a causal role in the acute-phase response'. However, they provided no information to document that the concentrations of IL- 6 found in these patients actually are capable of inducing the acute-phase responses seen. Moreover, although their level of statistical significance for the correlation between fever and IL-6 was highly significant $(P<0 \cdot 0001)$, the correlation coefficient, $r$, was 0.61 , and $r^{2}$ was only 0.37 . This value represents 'the proportion of the variance of $Y$ (temperature) that can be attributed to the linear regression on $X$ (IL-6), while $\left(1-r^{2}\right)$ is the proportion free from $X$ (IL-6)' (Snedecor \& Cochran, 1973). Therefore, even if there is a causal relationship between IL- 6 and temperature, $63 \%$ of the variation in body temperature can be attributed to factors other than the plasma concentration of IL-6.

Helle et al. (1987) reported at the same Workshop that $5 \mu \mathrm{g}$ purified IL-6/kg induces fever in rabbits. However, as in the studies using IL-1 or TNF, it is not known whether 
the amount injected that caused fever achieved plasma concentrations within the normal physiological or pathophysiological range. In recent studies in this laboratory, we have injected rats with a fever-inducing dose of LPS $(10 \mu \mathrm{g} / \mathrm{kg})$ and have measured the plasma concentrations of IL-6 (L. LeMay, A. J. Vander and M. J. Kluger, unpublished results). IL-6 levels rose in the plasma from non-detectable concentrations to an average of 3289 units $/ \mathrm{ml}$ by $60 \mathrm{~min}$ after injection with LPS. This rise in IL-6 preceded the rise in body temperature and was consistent with IL-6 being responsible for all or part of the fever. Overall, the correlation between fever and plasma IL-6 activity was 0.84 $(P<0.0025)$. The cerebrospinal fluid levels of IL-6 also was correlated with fever. When rats were injected intracerebroventricularly with recombinant human IL-6, large fevers developed. These fevers were completely blocked by intraperitoneal injection of the cyclooxygenase inhibitor indomethacin. It should be noted, however, that the dose of IL-6 necessary to induce fever following intracerebroventricular injection was extremely high ( $10^{6}$ units), several orders of magnitude higher than found in the cerebrospinal fluid during LPS-fever.

A similar problem with time-course has been reported by Ansel et al. (1987) for IL-1. They demonstrated both fever and increased serum IL-1 activity in rabbits as a result of u.v.-irradiation, and suggested that the chills and fever that often accompany sunburn may be attributable to IL-1. However, the temporal relationship between fever and plasma IL-1 activity was poor. In response to u.v.-irradiation, rabbits developed a fever that peaked at $5 \mathrm{~h}$, fell rapidly towards control values, and was close to baseline sometime between 7 and $24 \mathrm{~h}$; in contrast, the peak in plasma IL-1 activity occurred at 8 $\mathrm{h}$ and was still at this elevated level $24 \mathrm{~h}$ later. As noted by Ansel $e t$ al. (1987), the post-u.v. fever curve was not identical with the post-u.v. serum IL-1 activity, with the rabbit core body temperature decreasing even as the serum IL-1 activity was increasing. They suggested that the dissociation between fever and IL-1 activity may be a regulatory compensatory mechanism that prevented the harmful catabolic activities associated with prolonged fevers. Of course, another possibility is that circulating IL-1 is not the physiological EP in this situation.

One of the major problems preventing quantification in this field has been the lack of sensitive assays that would enable investigators to measure the plasma or extracellular concentrations of mediators such as IL-1. None of the published immunoassays for IL-1 (e.g. Kenney et al. 1987), is sensitive enough to measure the plasma concentrations of IL-1 that occur during infection. Moreover, although at the Workshop on Monokines and Other Nonlymphocytic Cytokines, several individuals did report on radioimmunoassays sensitive enough to measure the plasma concentrations of IL-1 in human beings, there is a poor correlation between this immunoactivity and bioactivity.

To summarize, it has not been shown that the administration of IL-1 (or other EP) in doses adequate to produce the plasma concentration of IL-1 (or other EP) induced by LPS or other exogenous pyrogen elicits a fever equal to that elicited by the exogenous pyrogen.

A second approach to testing a causal role of any mediator in the induction of fever in response to exogenous pyrogen is to use specific antibodies to block the action of the mediator. In an experiment in this laboratory, we found that i.p. injection of rats with antiserum against IL-1 $\alpha$ did not block LPS fever (Long et al. 1989). The dose of antiserum injected was sufficient to block fever caused by subsequent intramuscular injection of IL-1. Experiments are currently in progress to assess whether injection of antisera against IL-1 $\beta$ would influence LPS fever.

To attempt to determine whether TNF is involved in LPS-induced fever, we have injected rats i.p. with antisera to TNF or control sera (N. C. Long, S. L. Kunkel, A. J. 
Vander and M. J. Kluger, unpublished results). After $2 \mathrm{~h}$ each rat was injected with a fever-inducing dose of LPS $(10 \mu \mathrm{g} / \mathrm{kg})$. The rats injected with antisera to TNF had a slightly attenuated initial rise in body temperature; however, the second peak of the 'bimodal' fever was significantly larger. These findings suggest to us that TNF may be involved in the initiation or first phase of fever. Endogenously-produced TNF might then act (either directly or indirectly) as an endogenous antipyretic limiting the magnitude of fever; the removal or inactivation of this TNF by antisera to TNF removes this antipyretic action, thus resulting in the enhanced fever.

It is possible that a circulating EP is not the critical variable, but that elevated brain levels of EP are essential for fever development. Within the past few years it has become apparent that cells within the central nervous system are capable of producing IL-1 (Fontana et al. 1984; Guilian \& Lachman, 1985; Nieto-Sampedro \& Berman, 1987). In the study by Fontana et al. (1984) mice were injected with $50 \mu \mathrm{g}$ LPS i.p., and IL-1 was found in the brains of these mice. These observations have raised the possibility that in response to injection of LPS or other mediators of inflammation, it is the IL-1 produced locally by the brain (rather than the systemic plasma concentration of IL-1) that may be important in the development of fever. Unfortunately, no dose-response was reported in the study by Fontana et al. (1984). Assuming the mice weighed $25 \mathrm{~g}$, the dose of LPS they used would be equivalent to $2000 \mu \mathrm{g} / \mathrm{kg}$. This dose, in terms of fever induction, is probably a supramaximal one; it is unclear whether a dose of LPS that would produce a modest fever (e.g. half-maximal) would result in a significant rise in brain concentration of IL-1. In a more recent study, Coceani et al. (1988) found that injection of a fever-inducing dose of endotoxin did not result in any increase in IL-1 in the cerebrospinal fluid of the cat.

To our knowledge, there are no published studies indicating that TNF is produced by brain tissue. Grau et al. (1987) have shown that TNF is likely to be responsible for the pathogenesis of cerebral malaria in a murine model. This TNF, however, is presumably derived from adherence of macrophages to cerebral blood vessels, rather than being brain-derived TNF. At the Workshop on Monokines and Other Nonlymphocytic Cytokines, A. Billiau mentioned that IL- 6 has been found in the cerebrospinal fluid of infected patients. Grace Wong (from Genentech) then noted that glioblastoma cell lines have a high constitutive level of IL-6 mRNA. These findings raise the possibility that IL-6 produced in the central nervous system may play a role in fever.

In summary, although many cytokines can induce fever when injected or infused into experimental animals, it is still unclear which, if any, of the putative EP actually play a role in infection-induced fever.

\section{Effects of fever on nutrition}

Regardless of the role of specific cytokines in fever, an elevation in body temperature can have a direct effect on energy balance. The putative EPs, IL-1 and TNF, might also influence nutrition via other pathways (see Table 1). The direct effects of a febrile body temperature on metabolic rate, and the possible role of IL-1 and TNF in the anorexia of infection will be briefly reviewed.

Effect of fever on energy balance. During the rising phase of fever, when body temperature is below the thermoregulatory set-point, the febrile organism often increases its metabolic rate, presumably due to both shivering (e.g. Buskirk et al. 1964; Kerpel-Fronius et al. 1966; Stitt, 1973; Halmayagi \& Kinney, 1975; Lipton et al. 1979; Banet, 1981; Gagalo et al. 1983), and non-shivering thermogenesis (Blatteis, 1976; Horwitz \& Hanes, 1976; Szekely \& Szelenyi, 1979). 
Once body temperature has reached the elevated thermoregulatory set-point that occurs during fever, the plateau phase of fever, metabolic rate may still be elevated, probably the result of the well-known effect of temperature on most biochemical reactions (the $Q_{10}$ effect). For example, Tocco-Bradley et al. (1987) found that an infusion of monocyte-derived IL-1 (undoubtedly contaminated with other cytokines) into rats resulted in a significant increase in resting energy expenditure during the plateau phase. However, metabolic rate may not always be elevated during fever. In an earlier study by Tocco-Bradley et al. (1986), they found that the resting energy expenditure of rats infused with mouse recombinant IL-1, was actually reduced during the plateau phase of fever compared with controls. Duggan et al. (1986) noted a similar finding in children infected with measles. The reports of decreased metabolic rate during infection may be the result of other acute-phase responses of cytokines that result in decreased muscular activity and increased sleep (see Table 1).

Effects of inflammatory cytokines and food intake. Loss of appetite is a prominent feature of infection. For many years it was assumed that the loss of appetite with infection was the result of an elevation in body temperature (the so-called 'thermostatic theory of food intake') (Brobeck, 1981). However, in studies using antipyretic drugs and central injections of pyrogens, McCarthy et al. $(1984,1986)$ showed that the anorexia produced by injection of bacterial endotoxin or inflammatory mediators was not a direct result of the development of fever.

There is some evidence that the anorexia of infection is an adaptive host defence response. For example, pathogen-injected mice that were force-fed amounts of food that brought their intakes up to those of saline $(9 \mathrm{~g}$ sodium chloride/l)-injected controls were more likely to die than pathogen-injected mice allowed to express their anorexia (Murray \& Murray, 1979). This anorexia might contribute to a phenomenon known as 'nutritional immunity', in which reduced food intake may decrease the availability of nutrients to pathogenic organisms (Murray \& Murray, 1977; Weinberg, 1978; Kluger \& Rothenburg, 1979).

Support for the hypothesis that the anorexia of infection is a host defence response to infection, rather than a passive by-product of infection, comes from several studies showing that the cytokines IL-1 (McCarthy et al. 1985; Moldawer et al. 1988; Otterness et al. 1988) and TNF (Moldawer et al. 1988; Tracey et al. 1988) suppress food intake when injected or infused. However, as in the studies described previously regarding fever, it has not been proven that the anorexia of infection is actually attributable to these cytokines.

In a recent experiment in this laboratory, we studied the effects of continuous administration of IL-1 (via implanted minipumps) to rats (N. Mrosovsky, N. A. Molony, C. A. Conn and M. J. Kluger, unpublished results). Initially food intake and bodyweight declined, but within a few days of the onset of this infusion tolerance developed. Many hormones or hormone-like factors tend not to be secreted in a continuous fashion, and it is possible that the continuous release of IL-1 from these pumps resulted in 'down-regulation' of receptors responsible for the induction of anorexia. However, even when injected in bolus fashion, tolerance to the anorexigenic action of TNF has been reported (Kettelhut \& Goldberg, 1988; Moldawer et al. 1988; Socher et al. 1988; Tracey et al. 1988). In other experiments, mice bearing cachectin-secreting tumours lost considerably more weight than those with tumours not secreting TNF (Oliff et al. 1987). Since the tumours were growing, the dose of TNF was not controlled and it is possible that weight loss continued only because of an ever-increasing dose of TNF.

If tolerance develops to IL-1 and TNF, what then is responsible for the wasting (cachexia) that may accompany sustained presence of pathogens or tumour in the body? 
It is possible that the concentrations of IL-1 used in our study or that of TNF used in other studies were too high. Under more physiological or pathophysiological conditions, lower doses of these cytokines, perhaps secreted at irregular intervals, might have led to a long-term anorexia. An alternative explanation is, of course, that these cytokines may play a minor role in the long-term anorexia seen in chronic disease.

\section{REFERENCES}

Ansel, J. C., Luger, T. A. \& Green, I. (1987). Journal of Investigative Dermatology 89, 32-37.

Atkins, E. (1982). Yale Joumal of Biology and Medicine 55, 283-289.

Atkins, E. \& Bodel, E. (1974). In The Inflammatory Process, vol 3, 2nd ed., pp. 467-511 [B. W. Zweifach, L. Grant and T. McCluskey, editors]. New York: Academic Press.

Banet, M. (1981). Experientia 37, 1302-1304.

Beeson, P. B. (1948). Journal of Experimental Medicine 88, 267-278.

Bernheim, H. A. (1986). Yale Journal of Biology and Medicine 59, 151-158.

Billiau, A. \& van Damme, J. (1987). Journal of Leukocyte Biology (International Workshop on Monokines and Other Nonlymphocytic Cytokines) 42, 553-554.

Billroth, T. (1864-5). Archiv für Klinische Chirurgie 6, 372-495.

Blatteis, C. M. (1976). Journal of Applied Physiology 40, 29-34.

Brobeck, J. R. (1981). In Body Weight Regulatory System: Normal and Disturbed Mechanisms, pp. 1-9 [L. A. Cioff, W. P. T. James and T. B. Van Itallie, editors]. New York: Raven Press.

Burdon-Sanderson, J. (1876). Practitioner 16, 257.

Buskirk, E. R., Thompson, R. H., Rubenstein, M. \& Wolff, S. M. (1964). Journal of Applied Physiology 19, 907-913.

Cabanac, M., Duclauz, R. \& Gillet, A. (1970). Physiology and Behavior 5, 697-704.

Cabanac, M. \& Massonnet, B. (1974). Journal of Physiology 238, 561-568.

Coceani, F., Lees, J. \& Dinarello, C. A. (1988). Brain Research 446, 245-250.

Cooper, K. E., Cranston, W. I. \& Honour, A. J. (1967). Journal of Physiology 191, 325-337.

Cooper, K. E., Cranston, W. I. \& Snell, E. S. (1964). Clinical Science 27, 345-356.

Dinarello, C. A. (1984). Reviews of Infectious Diseases 6, 51-95.

Dinarello, C. A., Bernheim, H. A., Duff, G. W., Le, H. V., Nagabhushan, T. L., Hamilton, N. C. \& Coceani, F. (1984). Journal of Clinical Investigation 74, 906-913.

Dinarello, C. A., Cannon, J. G., Wolff, S. M., Bernheim, H. A., Beutler, B., Cerami, A., Figari, I. S., Palladino, M. A. Jr \& O'Connor, J. V. (1986). Journal of Experimental Medicine 163, 1433-1450.

Duggan, M. B., Alwar, J. \& Milner, R. D. G. (1986). Archives of Disease in Childhood 61, 61-66.

Feldberg, W. \& Scott, G. M. (1984). Journal of Physiology 355, 28P.

Fontana, A., Weber, E. \& Dayer, J.-M. (1984). Journal of Immunology 133, 1696-1698.

Gagalo, I. T., Hac, E. E. \& Korolkiewicz, K. Z. (1983). European Journal of Pharmacology 96, 193-200.

Grau, G. E., Fajardo, L. F., Piguet, P.-F., Allet, B., Lambert, P.-H. \& Vassalli, P. (1987). Science 237, 1210-1212.

Guilian, D. \& Lachman, L. B. (1985). Science 228, 497-499.

Halmayagi, D. F. J. \& Kinney, J. M. (1975). Surgery 77, $492-497$.

Helle, M., de Groot, E. R., Brakenhoff, J. P. J., Schaap, O. L. \& Aarden, L. A. (1987). Journal of Leukocyte Biology (International Workshop on Monokines and Other Nonlymphocytic Cytokines) 42, 555.

Horwitz, B. A. \& Hanes, G. E. (1976). American Journal of Physiology 230, 637-642.

Jackson, D. L. (1967). Journal of Neurophysiology 30, 586-602.

Kampschmidt, R. F. \& Jones, T. (1985). Proceedings of the Society for Experimental Biology and Medicine 180, 170-173.

Kenney, J. S., Masada, M. P., Eugui, E. M., Delustro, B. M., Mulkins, M. A. \& Allison, A. C. (1987). Journal of Immunology 138, 4236-4242.

Kerpel-Fronius, S., Kiss, A. \& Than, G. (1966). Acta Physiologica Academiae Scientiarum Hungaricae 29, 267-272.

Kettelhut, I. C. \& Goldberg, A. L. (1988). Journal of Clinical Investigation 81, 1384-1389.

King, M. K. \& Wood, W. B. Jr (1958). Journal of Experimental Medicine 107, 291-303.

Kluger, M. J. (1979). Fever: its Biology, Evolution, and Function. Princeton: Princeton University Press.

Kluger, M. J. \& Liu, D. Y. (1989). In Clinical Ischemic Syndromes: Mechanisms and Consequences of Tissue Injury [G. B. Zelenock, editor]. St. Louis: Mosby Press. 
Kluger, M. J., Oppenheim, J. J. \& Powanda, M. C. (editors) (1985). Progress in Leukocyte Biology. New York: Alan Liss.

Kluger, M. J. \& Rothenburg, B. A. (1979). Science 203, 374-376.

Lipton, J. M., Dinarello, C. A. \& Kennedy, J. I. (1979). Proceedings of the Society for Experimental Biology and Medicine 160, 426-428.

Long, N. C., Kluger, M. J. \& Vander. A. J. (1989). In Thermoregulation: Research and Clinical Applications, [P. Lomax and E. Schonbaum, editors]. Basel: Karger.

McCarthy, D. O., Kluger, M. J. \& Vander, A. J. (1984). American Journal of Clinical Nutrition 40, 310-316.

McCarthy, D. O., Kluger, M. J. \& Vander, A. J. (1985). American Journal of Clinical Nutrition 42, $1179-1182$.

McCarthy, D. O., Kluger, M. J. \& Vander, A. J. (1986). Physiology and Behavior 36, 745-749.

Menkin, V. (1944). Science 100, 377.

Moldawer, L. L., Andersson, C., Gelin, J. \& Lundholm, K. G. (1988). American Journal of Physiology 254, G450-G456.

Morimoto, A., Murakami, N., Takada, M., Teshirogi, S. \& Watanabe, T. (1987). Journal of Physiology 391, 209-218.

Murray, M. J. \& Murray, A. B. (1977). Lancet 1, 113-125.

Murray, M. J. \& Murray, A. B. (1979). American Journal of Clinical Nutrition 32, 593-596.

Nathan, C. F. (1987). Journal of Clinical Investigation 79, 319-326.

Nieto-Sampedro, M. \& Berman, M. A. (1987). Journal of Neuroscience Research 17, $214-219$.

Nijsten, M. W. N., De Groot, E. R., Ten Duis, H. J., Klasen, H. J., Hack, C. E. \& Aarden, L. A. (1987). Lancet fi, 921.

Oliff, A., Defeo-Jones, D., Boyer, M., Martinez, D., Kiefer, D., Vuocolo, G., Wolfe, A. \& Socher, S. H. (1987). Cell 50, 555-563.

Oppenheim, J. J. (1986). Current Concepts. Kalamazoo, MI: Upjohn Company.

Otterness, I. G., Seymour, P. A., Golden, H. W., Reynolds, H. A. \& Daumy, G. O. (1988). Physiology and Behavior 43, 797-804.

Satinoff, E., McEwan, G. N. Jr \& Williams, B. A. (1976). Science 193, 1139-1140.

Sharp, F. R. \& Hammel, H. T. (1972). American Journal of Physiology 223, 77-82.

Snedecor, G. W. \& Cochran, W. G. (1973). Statistical Methods, 6th ed. Iowa: Iowa State University Press.

Snell, E. S. \& Atkins, E. (1968). In The Biological Basis of Medicine, pp. 397-419 [E. E. Bittar and N. Bittar, editors]. New York: Academic Press.

Socher, S. H., Friedman, A. \& Martinez, D. (1988). Journal of Experimental Medicine 167, $1957-1962$.

Stitt, J. T. (1973). Joumal of Physiology 232, 163-179.

Stitt, J. T. (1986). Yale Journal of Biology and Medicine 59, 137-149.

Szekely, M. \& Szelenyi, Z. (1979). Acta Physiologica Academiae Scientiarum Hungaricae 54, $389-399$.

Tocco-Bradley, R. T., Georgieff, M., Jones, C. T., Moldawer, L. L., Dinarello, C. A., Bistrian, B. R. \& Blackburn, G. L. (1987). European Journal of Clinical Investigation 17, 504-510.

Tocco-Bradley, R. T., Moldawer, L. L., Jones, C. T., Gerson, B., Blackburn, G. L. \& Bistrian, B. R. (1986). Proceedings of the Society for Experimental Biology and Medicine 182, 263-271.

Tracey, K. J., Wei, H., Manogue, K. R., Fond, Y., Hesse, D. G., Nguyen, H. T., Kuo, G. C., Beutler, B., Cotran, R. S., Cerami, A. \& Lowry, S. F. (1988). Journal of Experimental Medicine 167, 1211-1227.

Vaughn, L. K., Bernheim, H. A. \& Kluger, M. J. (1974). Nature 252, $473-474$.

Weber, O. (1864). Deutsche Klinik 16, 461.

Weinberg, E. D. (1978). Microbiological Reviews 42, 45-66. 